\title{
Construcción de Sistema Hidropónico Flotante ${ }^{1}$
}

\author{
J. Bosques, M. Sweat, R. Tyson, y R. Hochmuth²
}

Los aztecas maravillaron a los conquistadores españoles con sus huertos flotantes, y hoy, 500 años después, usted puede impresionar a sus amigos y vecinos con el suyo. Un sistema hidropónico flotante es fácil de construir y puede proveer tremendas cantidades de vegetales nutritivos para el uso en su hogar, y lo mejor de todo es que los sistemas hidropónicos evitan muchos problemas de plagas asociados con el suelo. Esta guía sencilla le demostrará como construir su propio hidropónico flotante usando materiales disponibles localmente a un costo de alrededor de $\$ 50.00$ (Figura 1).

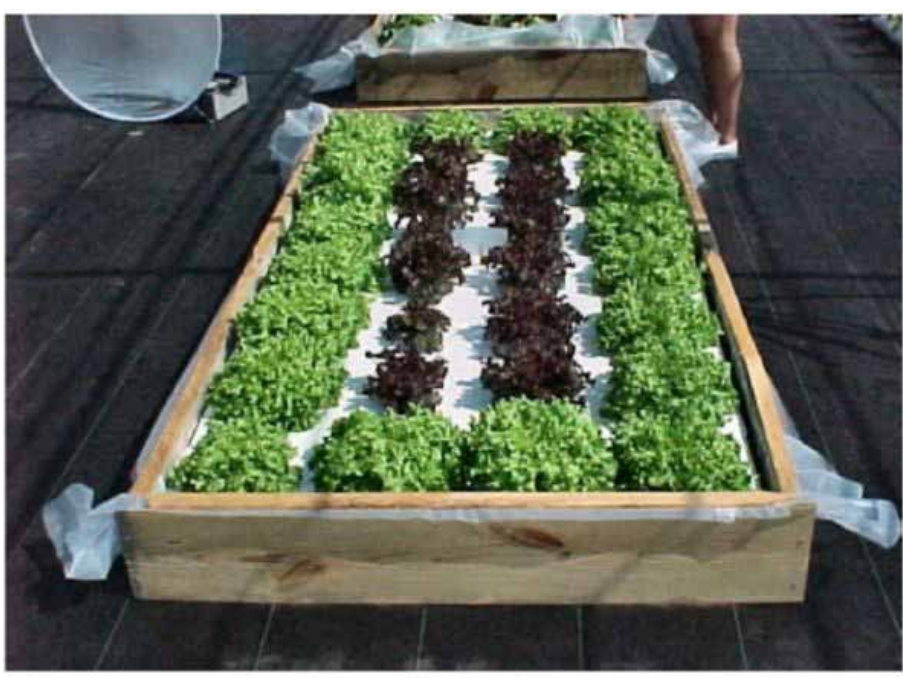

Figure 1. Lechuga en sistema hidropónico flotante.

\section{Construcción Paso por Paso}

- Construya un marco rectangular usando tablas de madera tratada 2-por-6 pulgadas o 2-por-8 pulgadas. El marco debe ser cuatro pies de ancho, una pulgada de grosor y ocho pies de largo. Este tamaño elimina la necesidad de recortar la plancha flotante de poliestireno (styrofoam), sin embargo, el tamaño puede variar de acuerdo a su necesidad particular.

- Cubra el marco con una capa de plástico polietileno de un grosor 6-mil para formar un contenedor para la solución nutritiva. Asegúrese de que el área en el cual coloque el sistema hidropónico flotante no tenga inclinación, esté libre de piedras y otros materiales abrasivos los cuales puedan romper la capa de plástico.

- Asegure un extremo de la capa de plástico en el tope del marco con listones plásticos o de madera de un grosor de 1- por-2 usando tornillos de madera o clavos pequeños.

- Coloque la plancha de poliestireno con medidas 4-por-8 y $1 \frac{1 / 2}{2}$ pulgadas de grosor dentro del marco. Asegúrese de que los bordes de la plancha de poliestireno tengan suficiente espacio para permitir el movimiento de este con el nivel de agua. Si es necesario, ajuste el marco para amoldarse al ángulo de la plancha de poliestireno. La plancha de ploiestireno creará una plataforma flotante dentro del marco de madera que ha construido.

1. Este documento, HS1210, es uno de una serie de publicaciones del Departemento de Horticultura, Servicio de Extensión Cooperativa de la Florida, Instituto de Alimentos y Ciencias Agrícolas, Universidad de la Florida. (UF/IFAS). Fecha de primera publicación: January 2013. Visite nuestro sitio web EDIS en <http://edis.ifas.ufl.edu>.

2. Jonael Bosques, agente de Extension I, Marion County; Michael Sweat, director de Extensión IV, Duval County; Richard Tyson, director de Extension II, Orange County; y Robert Hochmuth, agente de Extension IV, Suwannee Valley Agricultural Extension Center. Cooperative Extension Service, Institute of Food and Agricultural Sciences, University of Florida, Gainesville, FL 32611. 
- Llene el sistema con aproximadamente 20 galones de agua. El agua forzará la capa de plástico a moverse y amoldarse al marco. Asegure el lado contrario del plástico al tope del marco como se hizo anteriormente,

- Continúe llenando el sistema de agua hasta una profundidad de cinco pulgadas. Esté pendiente a la cantidad de galones que añada de agua para poder calcular la cantidad de nutrientes que esta lleva.

- Añada el fertilizante soluble en agua (como el 20-20-20) con micronutrientes, a una tasa de dos cucharaditas de fertilizante por cada galón de agua usado en el sistema. En adición, añada sal de Epsom (sulfato de magnesio) a una tasa de una cucharadita por cada galón de agua. Utilice una escoba suave para mezclar el agua y fertilizante en el huerto o disuelva estos en un cubo antes de añadirlos al agua (Figura 2). Es más seguro mezclar las soluciones separadas en cubos plásticos separados para evitar la reacción entre fertilizantes.

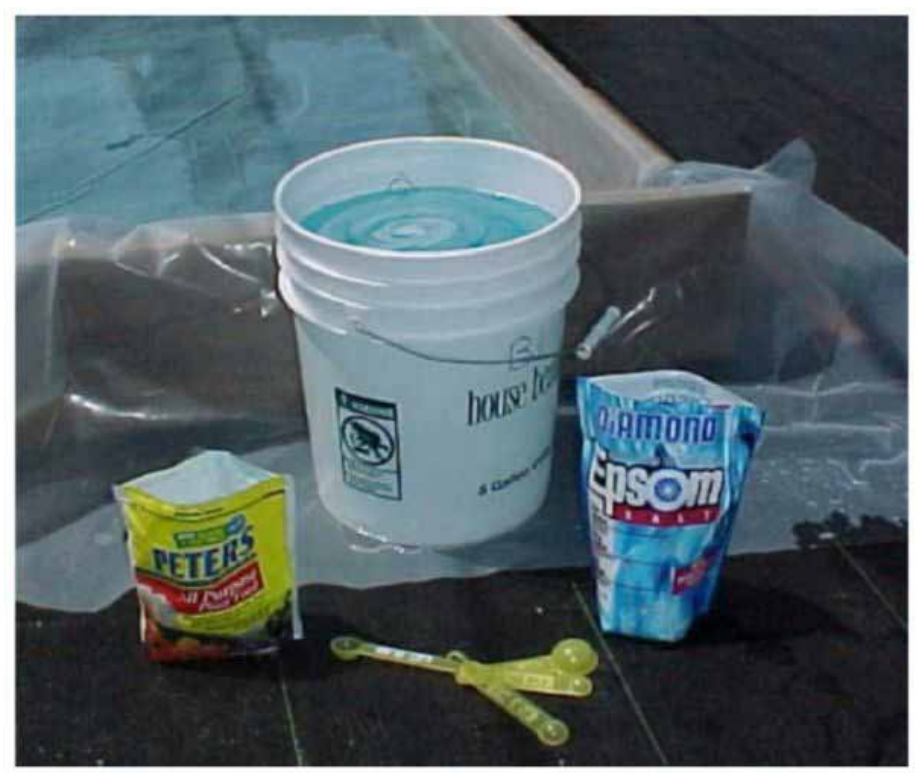

Figure 2. Nutrientes necesarios para el sistema hidropónico flotante.

- Lluvia ligera tendrá poco efecto en la solución de su sistema hidropónico flotante; solo en caso de inundación excesiva requerirá un re-ajuste de fertilizante basado en la cantidad de agua añadida por lluvia. La solución en el sistema debe ser reemplazada periódicamente para condiciones óptimas de producción. Puede cultivar dos cosechas de vegetales de hoja en la misma solución antes de cambiarla y comenzar con la próxima.

- Contenedores disponibles conocidos como "net pots" (Figura 3) o vasos de poliestireno con cortes en el fondo pueden ser utilizados para depositar los transplantes.

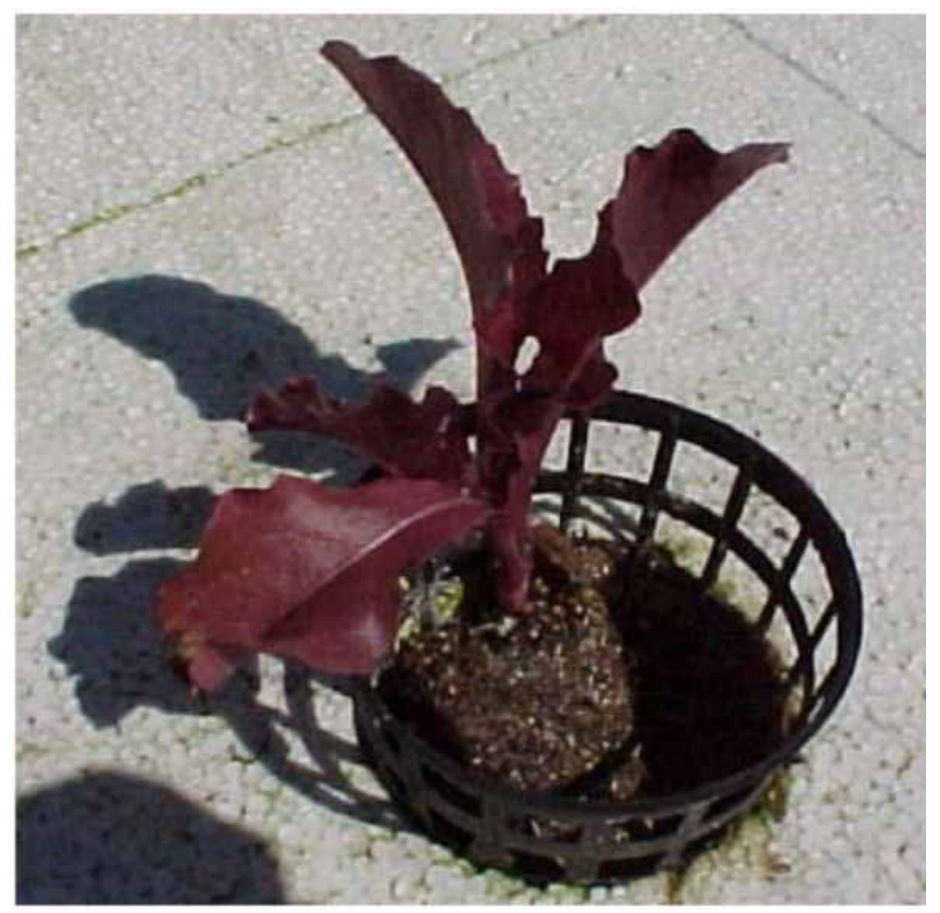

Figure 3. Transplante de lechuga en un "net pot".

- Use un serrucho o una navaja cortante para cortar los huecos en la plancha de poliestireno. Una mecha de taladro para cortar huecos puede ser utilizada. Esta debe medir $2 \frac{1}{2}$ pulgadas de diámetro si usa "net pots" o un vaso de poliestireno con cortes en el fondo y el tope recortado. Si usa "net pots" de 2 pulgadas de diámetro, requerirá una mecha de $13 / 4$ de pulgada de diámetro para cortar el hueco en la plancha de poliestireno flotante de $1 \frac{1 / 2}{2}$ pulgadas de grueso (Figura 4). El tamaño del hueco debe permitir que el fondo del "net pot" de las plantas toque el nivel de agua debajo de la plancha de poliestireno. Es muy importante que usted se asegure que una vez que se coloque el "net pot" en el hueco el fondo de este no se extienda más profundo que $1 / 16$ de pulgada debajo de la superficie del agua! Esto permite que la masa de raíces absorba agua sin estar totalmente sumergida, lo que puede conducir la planta a humedad excesiva y falta de oxígeno lo cual puede resultar en la muerte de la misma.

- El espacio óptimo para las plantas es de seis pulgadas entre plantas y 12 pulgadas entre líneas. Para un sistema de 8 pies por 4 pies de área, puede contar con un espacio para 32 plantas.

- Los transplantes para este sistema deben ser crecidos hasta tener suficientes raíces desarrolladas en un medio de cultivo sin suelo. Estos pueden ser crecidos en casa en diferentes envases o crecidos en pastillas compresas de fibra de coco o musgo. 


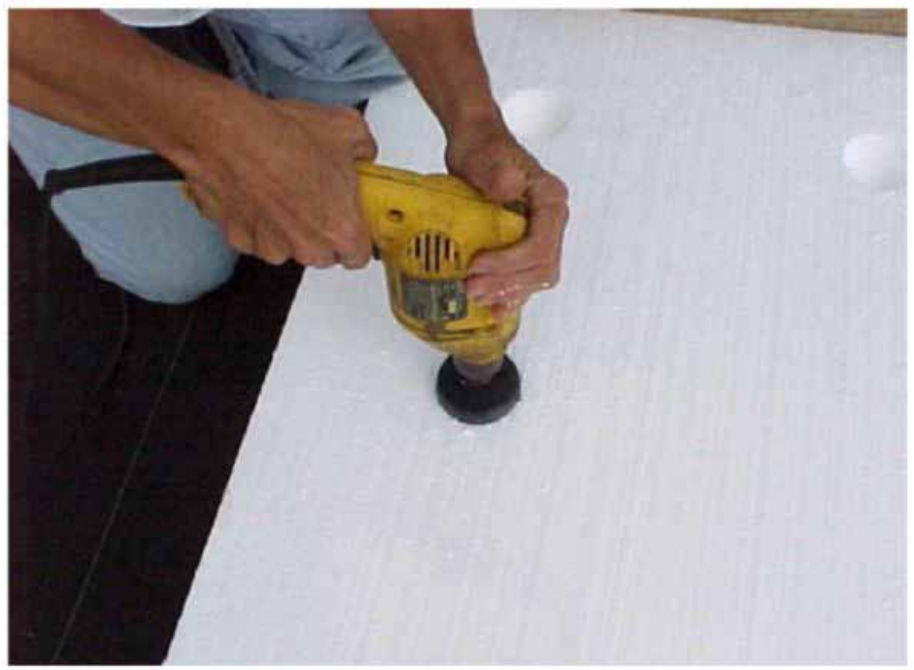

Figure 4. Taladrando huecos en la plancha de poliestireno para colocar los transplantes.

- Coloque los transplantes directamente en los vasos.

Utilice palillos de diente si desea para aguantar las plantas en la posición correcta. No remueva el medio de cultivo del transplante.

- El aspecto más crítico es la profundidad del "net pot" o la masa radicular de los transplantes y su contacto con la solución nutritiva. Un cubo de transplante o un medio en forma de disco con fondo plano absorberá más agua que un medio puntiagudo. Si el medio parece estar muy mojado, vire el cubo para reducir el área de contacto con la solución.

- Luego de colocar el transplante en el "net pot" u otro envase, no añada mas sustituto de suelo o medio de cultivo dentro del mismo ya que esto resultará en humedad excesiva y falta de oxigenación al área de la raíz (Figura 5).

- Añada agua adicional y fertilizante como sea necesario para mantener la plataforma de poliestireno flotando sobre una profundidad de 5 pulgadas o más de solución.

\section{Cultivos}

Varios cultivos de hoja como la lechuga (romana, Boston, bibb, etc., Figura 6), col de mostaza, mizuna, menta y col crecen bien durante la temporada fresca. Hay menos opciones para la temporada caliente, sin embargo, albahaca, acelga, pepinos, berro y algunas flores de corte como Zinnia y girasoles han crecido bien en este sistema. El crecer cultivos en un sistema hidropónico flotante no promete que todos los problemas enfrentados en la época caliente en

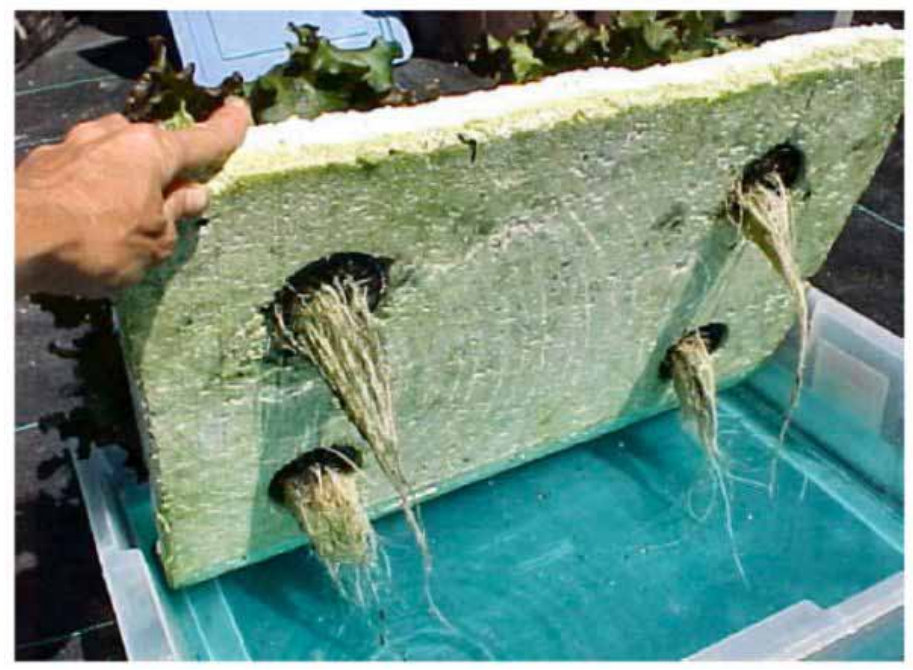

Figure 5. Sistema radicular de lechuga hidropónica.

Florida desaparecerán, pero provee una alternativa viable al cultivo tradicional.

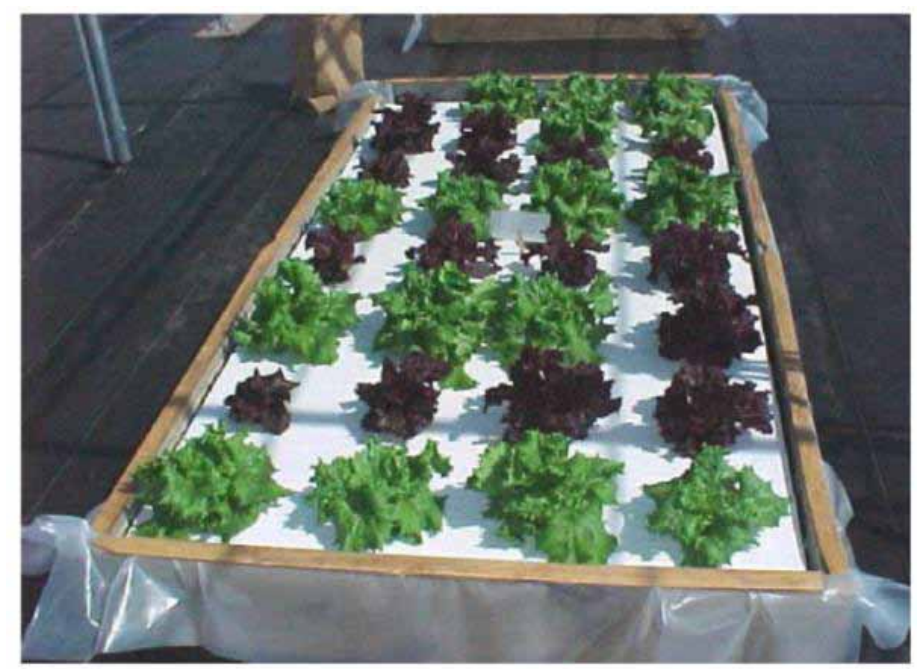

Figure 6. Lechuga saludable creciendo en un sistema hidropónico flotante tradicional con medidas 4 X8.

No todos los cultivos son viables para el sistema hidropónico flotante, sin embargo, aquellos que poseen raíces pequeñas y de crecimiento corto generalmente son ideales. Aquellos cultivos que prefieren raíces húmedas crecerán mejor que aquellos que prefieren condiciones secas. Por ejemplo, el berro crece muy bien, la pervinca no crece bien en el sistema hidropónico flotante.

\section{Selección de contenedores}

Esta publicación sirve como una guía para la construcción de un sistema hidropónico flotante de 4X8 pies usando madera y una cubierta plástica. Muchos contenedores más simples pueden ser utilizados para hacer su sistema. 
Algunos ejemplos incluyen: una piscina para niños, contenedores de almacenaje plásticos, botes de basura, cubos de agua. Muchas formas y tamaños pueden funcionar, pero estos deben ser capaces de mantener un nivel de agua de 4 a 6 pulgadas de solución nutritiva para mejores resultados.

\section{Nueva Investigación}

Se están llevando a cabo varias investigaciones con plantas como el tomate en sistemas flotantes indica que plantas más grandes requieren más volumen de raíces sobre el nivel de agua (más espacio de aire) para producir un rendimiento significativo. Para producir más masa radicular sobre el agua, usted podría probar un sistema que utiliza dos planchas de poliestireno superpuestas una encima de la otra con huecos hechos en la de abajo y un hueco de 6 pulgadas en la de arriba para acomodar las raíces superficiales. Rellene el hueco en la plancha superior con perlita, vermiculita u otro medio de cultivo. Plante vegetales o flores de la misma forma que lo haría en un huerto norman. Los resultados preliminares demuestra que este método parece dar resultado si el fertilizante usado en plantas jóvenes es liviano hasta que lar raíces de estas se desarrollen y lleguen hasta la solución debajo de las planchas de poliestireno.

Los pimientos y tomates son retadores para estos sistemas debido a que requieren una cantidad alta de nutrientes y calcio. La podredumbre de la fruta en el área del capullo es causado por niveles bajos de calcio en la fruta. Se puede suplementar los niveles de calcio en adición a la receta antes descrita. Estos productos de calcio son disponibles en muchos suplidores de jardinería.

\section{Recursos Adicionales}

Para más información en producción hidropónica, visite la pagina web http://smallfarms.ifas.ufl.edu. Copias en DVD en el tópico de construcción de sistemas hidropónicos flotantes puede ser adquirida por $\$ 15.00$, mas impuesto contactando la librería de IFAS al (352) 392-1764 o en línea en la dirección http://www.ifasbooks.ufl.edu,DVD295.

El video también está disponible en línea en la página web Virtual Field Day localizada en http://vfd.ifas.ufl.edu como parte de una serie de módulos en video acerca de hidropónicos.

\section{Suplidores de Productos Hidropónicos}

Aquatic Ecosystems, Inc. - http://aquaticeco.com 1-877$347-4788$ - net pots, kits para pasatiempo, materiales de hidroponía.
Hydrogardens, Inc. - http://www.hydrogarden.com 1-800634-6362 - "net pots", equipo de hidroponía.+-

Verti-Gro, Inc. - http://www.vertigro.com 1-352-347-9888 sistemas y equipo de hidroponía vertical.

CropKing, Inc. - http://www.cropking.com 1-800-321-5656 - equipo de hidroponía, invernaderos pequeños.

Worm's Way, Inc. - http://www.wormsway.com 1-800-2839676 - equipo de hidroponía, kits para pasatiempo.

Nota: Esta es una lista parcial de suplidores de materiales y equipos. La mención de estos suplidores no tiene la intención de ser un endoso de su producto o una preferencia sobre otros suplidores. 